\title{
An alternative to hydrogenation processes. Electrocatalytic hydrogenation of benzophenone
}

\author{
Cristina Mozo Mulero, Alfonso Sáez ${ }^{*}$ Jesús Iniesta and Vicente Montiel
}

\section{Full Research Paper}

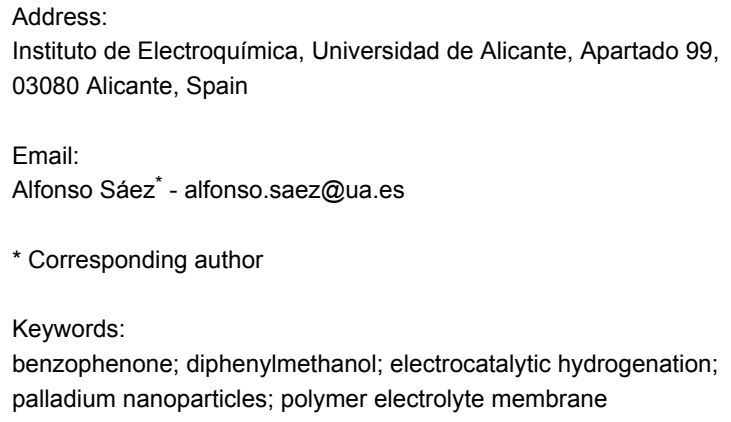

Beilstein J. Org. Chem. 2018, 14, 537-546. doi:10.3762/bjoc. 14.40

Received: 22 December 2017

Accepted: 15 February 2018

Published: 01 March 2018

This article is part of the Thematic Series "Electrosynthesis II".

Guest Editor: S. R. Waldvogel

(c) 2018 Mozo Mulero et al.; licensee Beilstein-Institut. License and terms: see end of document.

\begin{abstract}
The electrocatalytic hydrogenation of benzophenone was performed at room temperature and atmospheric pressure using a polymer electrolyte membrane electrochemical reactor (PEMER). Palladium (Pd) nanoparticles were synthesised and supported on a carbonaceous matrix $(\mathrm{Pd} / \mathrm{C})$ with a $28 \mathrm{wt} \%$ of $\mathrm{Pd}$ with respect to carbon material. $\mathrm{Pd} / \mathrm{C}$ was characterised by transmission electron microscopy (TEM), and thermogravimetric analysis (TGA). Cathodes were prepared using Pd electrocatalytic loadings $\left(\mathrm{L}_{\mathrm{Pd}}\right)$ of 0.2 and $0.02 \mathrm{mg} \mathrm{cm}^{-2}$. The anode consisted of hydrogen gas diffusion for the electrooxidation of hydrogen gas, and a $117 \mathrm{Nafion}$ exchange membrane acted as a cationic polymer electrolyte membrane. Benzophenone solution was electrochemically hydrogenated in EtOH/water $(90 / 10 \mathrm{v} / \mathrm{v})$ plus $0.1 \mathrm{M} \mathrm{H}_{2} \mathrm{SO}_{4}$. Current densities of 10,15 and $20 \mathrm{~mA} \mathrm{~cm}{ }^{-2}$ were analysed for the preparative electrochemical hydrogenation of benzophenone and such results led to the highest fractional conversion $\left(\mathrm{X}_{\mathrm{R}}\right)$ of around $30 \%$ and a selectivity over $90 \%$ for the synthesis of diphenylmethanol upon the lowest current density. With regards to an increase by ten times the Pd electrocatalytic loading the electrocatalytic hydrogenation led neither to an increase in fractional conversion nor to a change in selectivity.
\end{abstract}

\section{Introduction}

Hydrogenation is a common procedure applied in organic chemistry industry based on the use of an external hydrogen source, generally carried out under moderate experimental conditions of high temperature (until $673 \mathrm{~K}$ ) and high-pressure (even $350 \mathrm{~atm}$ ). Even though the hydrogenation is performed using either homogeneous or heterogeneous catalysts to en- hance chemical kinetics, a number of side reactions reduces the selectivity of the chemical reaction providing also complex and cost-ineffective work-up procedures [1-3]. Alternatively, electrocatalytic hydrogenation has emerged as a technique driven by its operational mild conditions, i.e., in situ "active hydrogen" generation, room temperature and atmospheric pressure, and 
higher selectivity [4-10]. This electrochemical "active hydrogen" generation is performed under a cathodic polarization and such mechanism of an unsaturated organic compound (e.g., $\mathrm{Y}=\mathrm{X}$ ) still remains undertrained. Nonetheless, the steps likely involved in this electrochemical process by the literature [1115] are as follows: (i) formation of adsorbed hydrogen $\mathrm{MH}_{\mathrm{ads}}$ (defining " $\mathrm{M}$ " as a metal adsorption site and $\mathrm{H}_{\mathrm{ads}}$ as atomic adsorbed hydrogen), (ii) adsorption of the organic molecule on a support site (two distinct adsorption sites are considered) and, (iii) electrocatalytic hydrogenation of the organic molecule through the adsorbed atomic hydrogen. It is important to note that, formation of "active hydrogen" is the main step in this process and hydrogen-active powder electrocatalysts such as $\mathrm{Pd} / \mathrm{C}, \mathrm{Pt} / \mathrm{C}$ or Raney-nickel have been demonstrated as the optimal choice $[16,17]$. Moreover, the organic molecule adsorption rate must be faster than that one associated with the recombination of $\mathrm{MH}_{\mathrm{ads}}$ to form diatomic hydrogen gas; otherwise electrocatalytic hydrogenation does not occur or displays a low Faraday efficiency because of the fact that diatomic hydrogen formation is not the main reaction, but a competitive one. Clearly, from the above mechanistic steps, the lower the "atomic active hydrogen" generation rate, the more efficient the electrocatalytic hydrogenation process; thus, the higher the used current density, the lower the obtained efficiency. Moreover, selectivity of electrocatalytic hydrogenation of ketones to alcohols is performed in acidic medium as an optimal reaction medium [5].

Currently, developments in nanostructured materials and polymeric solid exchange membranes have led the field of polymer electrolyte membrane fuel cells (PEMFC) to become a mature technology [18-20]. In this regard, a polymer electrolyte membrane electrochemical reactor (PEMER) has already been defined and manufactured to implementing all PEMFC technology advantages for both inorganic and organic electrosynthetic processes [21]. It is worth noting that the use of a polymer electrolyte membrane electrochemical reactor (PEMER) allows obtaining several advantages compared to the use of conventional electrochemical reactors, as follows: i) nanostructurated electrocatalysts can be utilized for both cathodic and anodic reactions, ii) a solid polymer electrolyte is used instead of a conventional electrolyte and iii) a decrease of the anode-cathode gap reduces ohmic drop at the whole process. In the case of organic electrosynthesis, electrocatalytic hydrogenation of aromatic ketones, specifically acetophenone, has been recently carried out $[22,23]$ achieving a high selectivity using the above-mentioned technology. In this work, we have chosen benzophenone, as a more complex aromatic ketone dictated by the presence of two phenyl rings, in order to analyse fractional conversion and selectivity of formed products. Here, the main obtained product is diphenylmethanol (ketone conversion to alcohol) as a high added value product in chemical industry. Even though several research groups have reported in the literature fundamental aspects about the electrocatalytic hydrogenation of benzophenone as well as its electrolytic performance at laboratory scale using $\mathrm{Pd}, \mathrm{Ni} / \mathrm{Pd}$ or $\mathrm{Ni} / \mathrm{Pt}$ based either on massive or nanoparticulate cathodes [5,24-26]. The electrocatalytic hydrogenation of benzophenone has not been accomplished using a PEMER yet.

This work aims at exploring the electrocatalytic hydrogenation of benzophenone over palladium nanoparticles supported on carbon black based electrode using a PEMER. A nanoparticulate platinum gas diffusion electrode is used for the hydrogen oxidation reaction and a cationic exchange membrane is used as solid polymeric electrolyte. Fractional conversion, product yield and selectivity are presented upon the Pd electrocatalytic loading and current density. Moreover, the effect of the absence and presence of the supporting electrolyte upon the conversion and product yield of the electrochemical hydrogenation of benzophenone is explored.

\section{Results and Discussion}

Pd nanoparticles supported on Vulcan XC72R as electrocatalyst in cathodic reaction (electrocatalytic hydrogenation) were synthesised by reducing $\mathrm{K}_{2} \mathrm{PdCl}_{4}$ using $\mathrm{NaBH}_{4}$ in a water-in-oil (w/o) microemulsion (water/Brij@30/n-heptane). This methodology has been previously used in our laboratory [27,28]. We first explored the morphology, size and dispersion of Pd nanoparticles supported on Vulcan XC72R carbonaceous material ( $\mathrm{Pd} / \mathrm{C}$ electrocatalysts) using TEM micrographs. As shown in Figure 1a, a good dispersion of spherical Pd nanoparticles of about 4-5 nm size is obtained. As expected, EDX analysis of Pd nanoparticles displays palladium as the sole metal, as shown in Figure $1 \mathrm{~b}$. With respect to the $\mathrm{Pd}$ loading in the $\mathrm{Pd} / \mathrm{C}$ electrocatalyst, TGA results shown in Figure 1c lead to ca. 30 wt \% content. A high drop of weight is observed between $600 \mathrm{~K}$ and $700 \mathrm{~K}$ since carbonaceous support is volatilized until reaching a residual $\mathrm{PdO}$ content $\left(\mathrm{Pd}\right.$ in a $\mathrm{N}_{2} / \mathrm{O}_{2}$ atmosphere becomes a $\mathrm{PdO}$ species as stable residual weight when temperature is increased from $700 \mathrm{~K}$ to $1073 \mathrm{~K}$ ). From the stable residual weight in Figure 1c at higher temperature it can be estimated that there is a content of $32 \mathrm{wt} \%$ of $\mathrm{PdO}$ in the whole $\mathrm{Pd} / \mathrm{C}$ electrocatalyst, thereby confirming that the electrocatalyst can be considered as $\mathrm{Pd} / \mathrm{C}$ with $28 \mathrm{wt} \%$, by correcting the $\mathrm{PdO}$ value by subtracting the oxygen atomic percentage content. Thus, the above experimental wt \% value of $\mathrm{Pd}$ is in agreement with the theoretical one of $30 \mathrm{wt} \%$ as described in the experimental section.

Once the $\mathrm{Pd} / \mathrm{C}$ electrocatalyst characterisation was performed, $\mathrm{Pd} / \mathrm{C}$ based cathodes either with 0.2 or $0.02 \mathrm{mg} \mathrm{Pd}$ per $\mathrm{cm}^{2}$ 


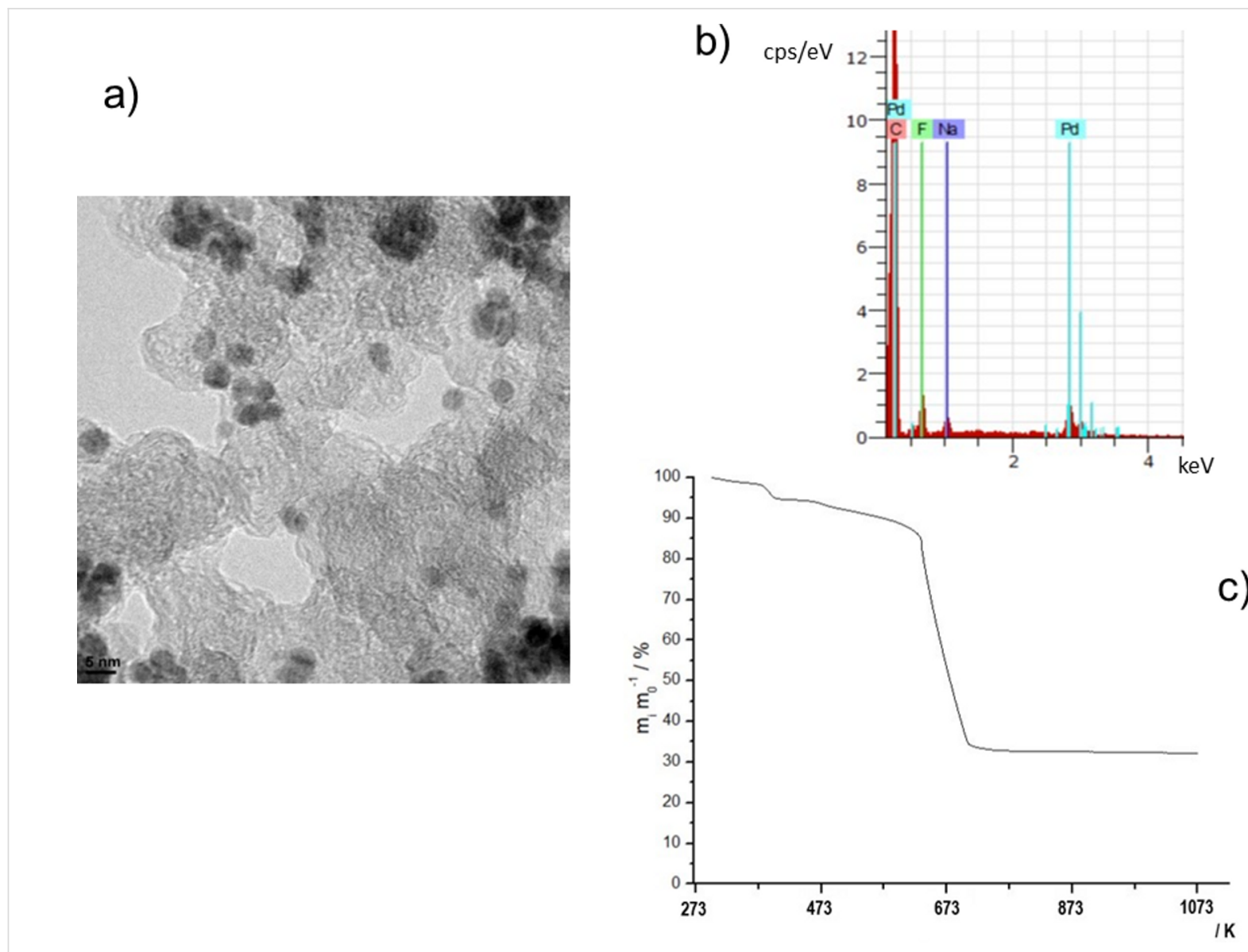

Figure 1: Characterisation of $\mathrm{Pd} / \mathrm{C}$ electrocatalyst. a) TEM micrograph. b) Energy dispersive $\mathrm{X}$-ray analysis (EDX). c) Thermogravimety analysis in $\mathrm{N}_{2} / \mathrm{O}_{2}(4 / 1)$ atmosphere at a heating slope of $10 \mathrm{~K} \mathrm{~min}^{-1}$ from $298 \mathrm{~K}$ to $1023 \mathrm{~K}$.

were prepared and characterised by SEM and cyclic voltammetry. A Pd/C to Nafion ratio was established at 60:40 for each electrocatalytic layer irrespectively of the Pd loading in the electrocatalytic layer. Figure 2 depicts the SEM micrographics using back scattering electrons for both $\mathrm{Pd}_{0.02} / \mathrm{C} / \mathrm{T}$ and $\mathrm{Pd}_{0.20} / \mathrm{C} / \mathrm{T}$ electrodes (nomenclature described in the experimental section) at different magnifications. The SEM image for the highest electrocatalytic loading discloses a brighter appearance compared to the lowest one since backscattering electrons from high atomic weight (e.g., palladium) are brighter than lower atomic weight (e.g., carbon).

Apart from the SEM characterisation, the determination of the electrochemically active surface area (ESA) of the cathodic electrocatalytic layer is also crucial for the characterisation of both electrodes. In this regard, Figure 3 depicts the electrochemical behaviour of a $\mathrm{Pd}_{0.20} / \mathrm{C} / \mathrm{T}$ electrode in $0.5 \mathrm{M} \mathrm{H}_{2} \mathrm{SO}_{4}$ using cyclic voltammetry $(\mathrm{CV})$ at a scan rate of $50 \mathrm{mV} \mathrm{s}^{-1}$ (potential interval of 0.1 and $1.2 \mathrm{~V}$ vs $\mathrm{Ag} / \mathrm{AgCl}$ ). The $\mathrm{CV}$ diagram shown in Figure 3 represents a typical pattern for the electrochemical behaviour of Pd bar electrode where a broad

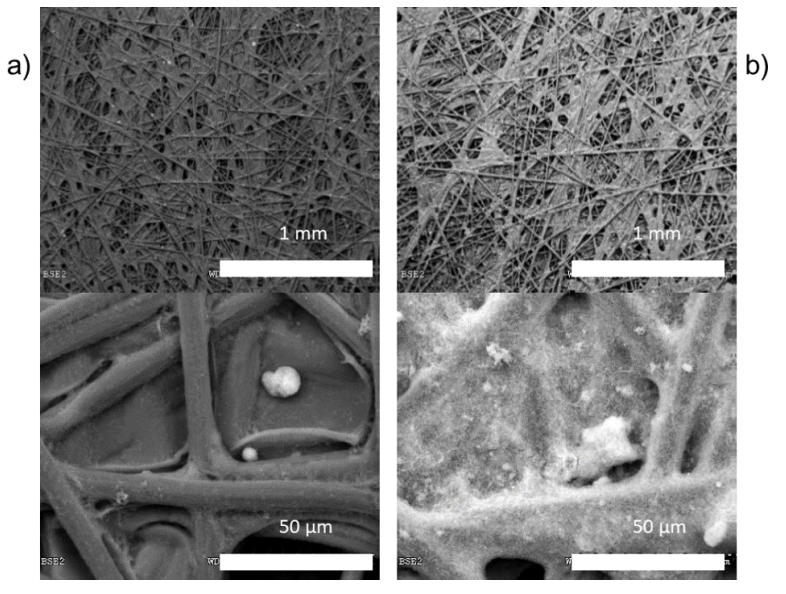

Figure 2: SEM images of (a) $\mathrm{Pd}_{0.02} / \mathrm{C} / \mathrm{T}$ and (b) $\mathrm{Pd}_{0.20} / \mathrm{C} / \mathrm{T}$ electrodes, with different magnifications.

anodic peak is associated to the oxidation of the Pd surface to $\mathrm{PdO}$ and then followed by a well-defined cathodic peak on the negative scan ascribed to the reduction of PdO to Pd [29]. From the coulombic charge integration of the cathodic peak on the 
$\mathrm{CV}$ in Figure 3 (shadowed region) can be accurately calculated the ESA value and roughness factor, as defined in the experimental section. The ESA value is calculated according to Equation 1 ,

$$
\mathrm{ESA}=\frac{Q_{\mathrm{Pd}}}{0.424 \cdot L_{\mathrm{Pd}} \cdot A_{\mathrm{geom}}}
$$

where $Q_{\mathrm{Pd}}(\mathrm{mC})$ is calculated from the coulombic charge integration from the cathodic peak after subtracting the double layer, $L_{\mathrm{Pd}}$ denotes the electrocatalytic loading expressed in $\mathrm{mg}$ of Pd per square centimetre of electrocatalytic layer, $A_{\text {geom }}\left(\mathrm{cm}^{2}\right)$ is the electrode geometric area and 0.424 refers to charge density expressed in $\mathrm{mC}$ per $\mathrm{cm}^{2}$ of Pd [29]. On the other hand, the roughness factor rf is also calculated according to Equation 2.

$$
\mathrm{rf}=\mathrm{ESA} \cdot L_{\mathrm{Pd}}
$$

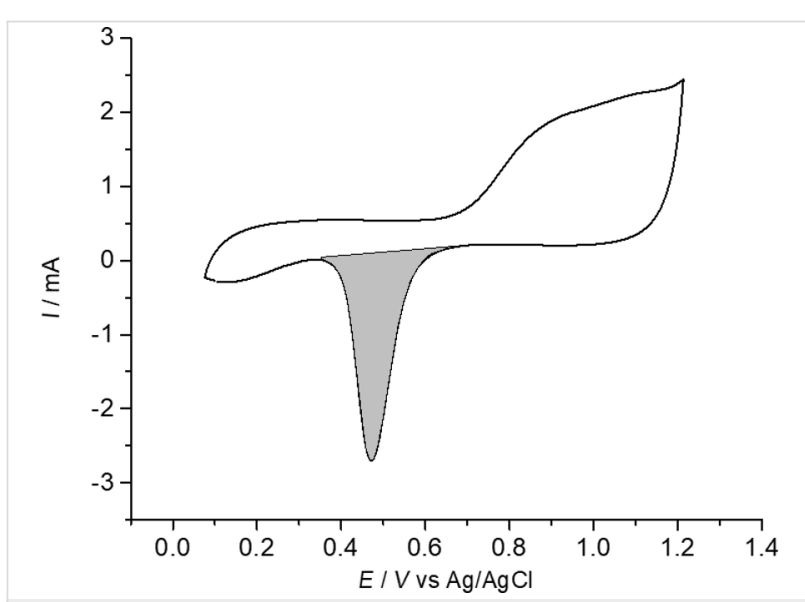

Figure 3: Cyclic voltammetric behaviour of $\mathrm{Pd}_{0.20} / \mathrm{C} / \mathrm{T}$ electrode in $0.5 \mathrm{M} \mathrm{H}_{2} \mathrm{SO}_{4}$. Scan rate: $50 \mathrm{mV} \mathrm{s}^{-1}$. Starting potential: $0.2 \mathrm{~V}$ vs Ag/AgCl. Positive scan.

Calculations of ESA and $\mathrm{rf}$ values were addressed for both $\mathrm{Pd}_{0.02} / \mathrm{C} / \mathrm{T}$ and $\mathrm{Pd}_{0.20} / \mathrm{C} / \mathrm{T}$ electrodes. It is worth noting that rf values denote real electrocatalytic surface area as a multiple factor of the theoretical geometric area. In this regard, rf values were 85 and 14 times the geometric area, whereas ESA values were 707 and 424 for $\mathrm{Pd}_{0.02} / \mathrm{C} / \mathrm{T}$ and $\mathrm{Pd}_{0.20} / \mathrm{C} / \mathrm{T}$ electrodes, respectively. The later ESA values indicate an increase of $67 \%$ of active surface area per weight unit, so the higher the electrocatalytic loading shown in a cathode electrocatalytic layer, the lower the electrochemically accessible surface per milligram. The above behaviour is likely attributed to a much thicker electrocatalytic layer for the $\mathrm{Pd}_{0.20} / \mathrm{C} / \mathrm{T}$ electrode compared to $\mathrm{Pd}_{0.02} / \mathrm{C} / \mathrm{T}$ electrode. Nonetheless, a thicker electrocatalytic layer is also detrimental for the accessibility of the electroactive species to the electrocatalytic metal surface, i.e., Pd nano- particles, mostly due to the appearance of bottlenecks or blockage of network across the electrocatalytic layer, or likely some of these Pd nanoparticles could be covered up each other so those ones would be hidden.

Once Pd nanoparticle-based cathodes were manufactured and characterised, electrolytic hydrogenation of benzophenone in a cathodic process and hydrogen oxidation reaction as the anodic process was performed using a PEMER. Figure 4 describes each one of reactions involved in both cathodic and anodic processes and, also, the particulate elements of the electrochemical reactor.

Thus, preparative electrocatalytic hydrogenation of benzophenone was performed using a PEMER with $\mathrm{Pd}_{0.02} / \mathrm{C} / \mathrm{T}$ and $\mathrm{Pd}_{0.20} / \mathrm{C} / \mathrm{T}$ electrodes. We first investigated the influence of current density, i.e., 10,15 and $20 \mathrm{~mA} \mathrm{~cm}^{-2}$, on the electrochemical hydrogenation using a $\mathrm{Pd}_{0.02} / \mathrm{C} / \mathrm{T}$ electrode with a coulombic charge passed of $2 \mathrm{~F}$ (theoretical coulombic charge established by Faraday' s Law by considering reaction of one mol of reagent). Figure 5 depicts the fractional conversion of benzophenone (expressed in percentage) versus the coulombic charge passed for all three current densities examined.

It should be noted that a higher fractional conversion of benzophenone of $25.8 \%$ is obtained for the lowest current density compared with values of $10.1 \%$ and $3.9 \%$ for current densities of 15 and $20 \mathrm{~mA} \mathrm{~cm}^{-2}$, respectively (see Table 1). Our findings are highly expected accordingly to the steps involved in the electrochemical hydrogenation mechanisms (vide supra). In this regard, after formation of $\mathrm{PdH}_{\mathrm{ad}}$, the recombination rate of this "atomic active hydrogen" into diatomic hydrogen gas should be slower than the adsorption rate of the organic compound over the cathode in order to prompt electrocatalytic hydrogenation; consequently, a low current density should favour the hydrogenation process instead of diatomic hydrogen formation as competitive and side reaction by considering a slow $\mathrm{PdH}_{\mathrm{ad}}$ formation rate of this.

HPLC analysis was performed for the identification and quantification of the benzophenone depletion and final product formation from the electrocatalytic hydrogenation at $\mathrm{Pd}_{0.02} / \mathrm{C} / \mathrm{T}$ electrode. An inspection of the chromatograms confirms the formation of two final products corresponding to diphenylmethanol $\left(\mathrm{Ph}_{2} \mathrm{CHOH}\right)$ and diphenylmethane $\left(\mathrm{Ph}_{2} \mathrm{CH}_{2}\right)$. Table 1 compiles fractional conversion of $\mathrm{Ph}_{2} \mathrm{CO}\left(\mathrm{X}_{\mathrm{R}}\right)$, product yield of $\mathrm{Ph}_{2} \mathrm{CHOH}$ and $\mathrm{Ph}_{2} \mathrm{CH}_{2}(\eta)$, selectivity of $\mathrm{Ph}_{2} \mathrm{CHOH}(\xi)$ and cell voltage $\left(\Delta U_{\text {cell }}\right)$ for each current density over coulombic charge passed. It is worth noting that product yield for the $\mathrm{Ph}_{2} \mathrm{CHOH}$ is higher at low current density with an almost linear increase as a function of coulombic charge passed. Moreover, it 


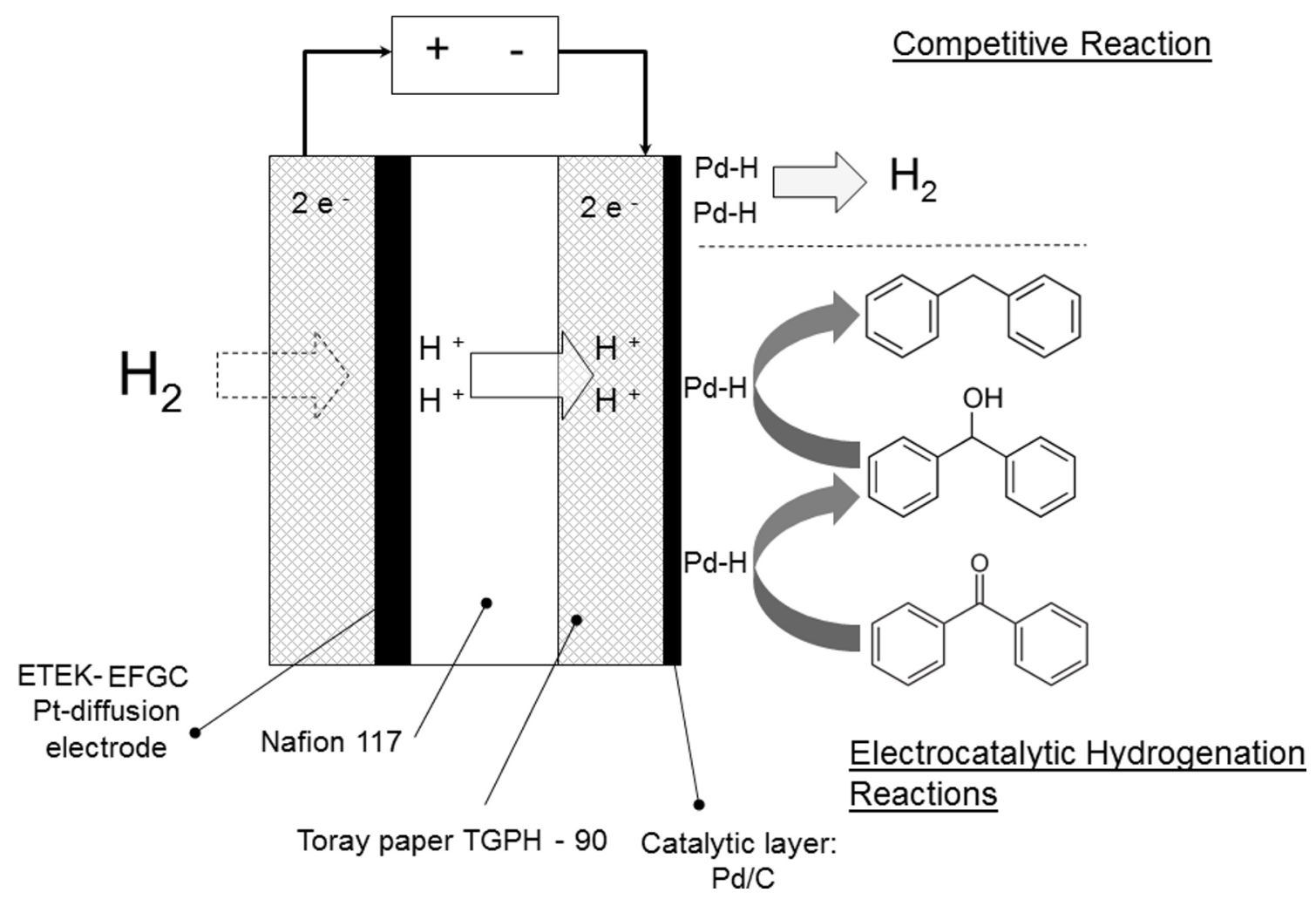

Figure 4: Scheme of all components of the electrochemical reactor including reactions involved in both anode and cathode.

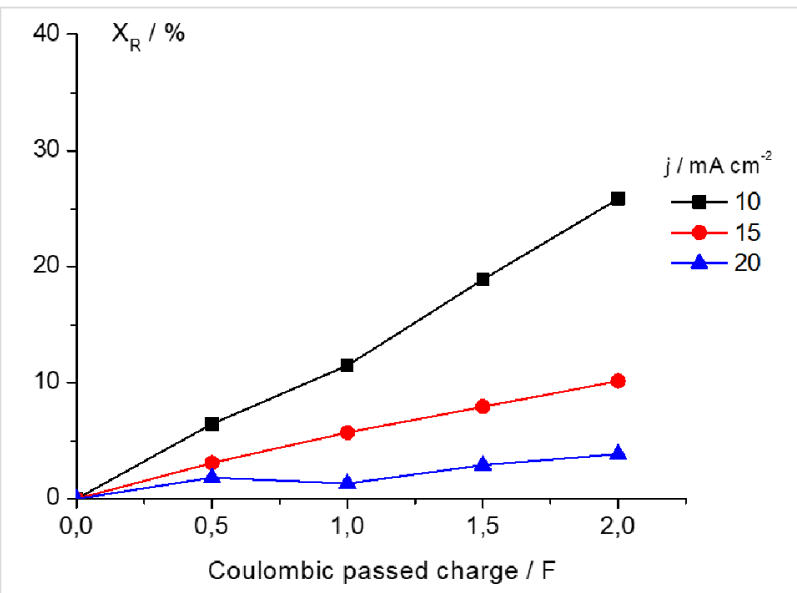

Figure 5: Fractional conversion of benzophenone as a function of coulombic passed charge using the PEMER; $0.5 \mathrm{M}$ benzophenone as starting solution in ethanol/ $\mathrm{H}_{2} \mathrm{O}(90: 10 \mathrm{v} / \mathrm{v})+0.1 \mathrm{M} \mathrm{H}_{2} \mathrm{SO}_{4} . \mathrm{Pd}_{0.02} / \mathrm{C} / \mathrm{T}$ electrode.

is noticed that the selectivity value generally over $90 \%$ is irrespective of the current density. Electrocatalytic hydrogenation of benzophenone was also performed using $\mathrm{Pd}_{0.00} / \mathrm{C} / \mathrm{T}$ electrodes, i.e., in the absence of the Pd electocatalyst, at $10 \mathrm{~mA} \mathrm{~cm}^{-2}$ demonstrated neither the electrochemical reduction of benzophenone nor the formation of alcohol or alkane derivatives.
Table 1 also depicts the average cell voltage from the electrocatalytic hydrogenation of benzophenone, with values of 0.2 , 0.3 and $0.5 \mathrm{~V}$ for 10,15 and $20 \mathrm{~mA} \mathrm{~cm}^{-2}$, respectively. More precisely, Figure 6 plots cell voltage versus time at $10 \mathrm{~mA} \mathrm{~cm}^{-2}$. In this case, a high cell voltage increase is observed from the open circuit voltage of around $0 \mathrm{~V}$ until the first stage of the electrocatalytic hydrogenation, followed by a cell voltage drop attributed to a decrease in IR drop of the membrane provoked by humidity lack of the membrane at either the anodic or cathodic sides when starting the electrocatalytic hydrogenation reaction. A similar variation of cell voltage versus time was also observed when using the rest of current densities.

Next we turn out to explore the influence of the Pd electrocatalytic loading on benzophenone conversion. Once again, electrocatalytic hydrogenation experiments were performed at constant current densities of 10,15 and $20 \mathrm{~mA} \mathrm{~cm}^{-2}$ using a manufactured cathode with a $\mathrm{Pd}$ electrocatalytic loading of $0.2 \mathrm{mg} \mathrm{cm}^{-2}\left(\mathrm{Pd}_{0.20} / \mathrm{C} / \mathrm{T}\right.$ electrode $)$. Results depicted in Figure 7 show again a higher benzophenone fractional conversion at lower current densities, as happened for the electrocatalytic hydrogenation using an electrode $\left(\mathrm{Pd}_{0.02} / \mathrm{C} / \mathrm{T}\right)$ with a 10 times lower Pd loading. Interestingly, benzophenone conversion performed at 15 and $20 \mathrm{~mA} \mathrm{~cm}^{-2}$ turned out to be slightly 
Table 1: Fractional conversion $\left(\mathrm{X}_{\mathrm{R}}\right)$, product yield for diphenylmethanol $\left(\eta_{\mathrm{Ph} 2 \mathrm{CHOH}}\right)$ and diphenylmethane $\left(\eta_{\mathrm{Ph} 2 \mathrm{CH} 2}\right)$, selectivity for diphenylmethanol $\left(\xi_{\mathrm{Ph} 2 \mathrm{CH}}\right)$ versus coulombic charge passed at constant current densities of 10,15 and $20 \mathrm{~mA} \mathrm{~cm}^{-2}$. $\mathrm{Pd}_{0.02} / \mathrm{C} / \mathrm{T}$ electrode. Benzophenone $(0.5 \mathrm{M})$ was used as starting solution in ethanol/water $(90: 10 \mathrm{v} / \mathrm{v})+0.1 \mathrm{M} \mathrm{H}_{2} \mathrm{SO}_{4}$.

\begin{tabular}{|c|c|c|c|c|c|c|}
\hline \multirow{2}{*}{$\begin{array}{c}j \\
{\left[\mathrm{~mA} \mathrm{~cm}^{-2}\right]}\end{array}$} & & \multicolumn{3}{|c|}{$Q_{\text {passed }}$} & & \multirow{2}{*}{$\begin{array}{c}\Delta U_{\text {cell }} \\
{[\mathrm{V}]}\end{array}$} \\
\hline & & 0.5 & 1.0 & 1.5 & 2.0 & \\
\hline \multirow{4}{*}{10} & $\mathrm{X}_{\mathrm{R}}$ & 6.5 & 11.5 & 18.9 & 25.8 & \multirow{4}{*}{0.2} \\
\hline & $\eta_{\mathrm{Ph} 2 \mathrm{CHOH}}$ & 4.1 & 9.2 & 16.9 & 22.4 & \\
\hline & $\eta \mathrm{Ph} 2 \mathrm{CH} 2$ & 0.9 & 1.1 & 1.6 & 1.6 & \\
\hline & $\xi_{\mathrm{Ph} 2 \mathrm{CHOH}}$ & 83 & 89 & 91 & 93 & \\
\hline \multirow{4}{*}{15} & $\mathrm{X}_{\mathrm{R}}$ & 3.1 & 5.7 & 7.9 & 10.1 & \multirow{4}{*}{0.3} \\
\hline & $\eta \mathrm{Ph} 2 \mathrm{CHOH}$ & 3.7 & 5.4 & 7.4 & 9.9 & \\
\hline & $\eta \mathrm{Ph} 2 \mathrm{CH} 2$ & 0 & 0 & 0.3 & 0.4 & \\
\hline & $\xi \mathrm{Ph} 2 \mathrm{CHOH}$ & 100 & 100 & 96 & 96 & \\
\hline \multirow{4}{*}{20} & $X_{R}$ & 1.8 & 1.3 & 2.9 & 3.9 & \multirow{4}{*}{0.5} \\
\hline & $\eta_{\mathrm{Ph} 2 \mathrm{CHOH}}$ & 0.9 & 1.7 & 2.5 & 3.0 & \\
\hline & $\eta \mathrm{Ph} 2 \mathrm{CH} 2$ & 0 & 0 & 0.3 & 0.4 & \\
\hline & $\xi_{\mathrm{Ph} 2 \mathrm{CHOH}}$ & 100 & 100 & 88 & 88 & \\
\hline
\end{tabular}

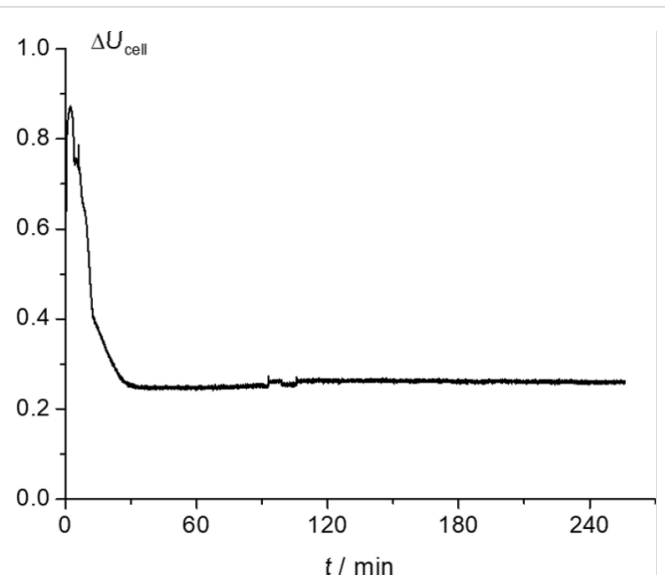

Figure 6: Plot of cell voltage versus time obtained from a preparative electrosynthesis performed at $10 \mathrm{~mA} \mathrm{~cm}^{-2}, \mathrm{Pd}_{0.02} / \mathrm{C} / \mathrm{T}$ electrode; $0.5 \mathrm{M}$ benzophenone as starting solution in ethanol/water $(90: 10 \mathrm{v} / \mathrm{v})$ plus $0.1 \mathrm{M} \mathrm{H}_{2} \mathrm{SO}_{4}$.

lower for the $\mathrm{Pd}_{0.20} / \mathrm{C} / \mathrm{T}$ electrode (vide infra). In this regard, Figure 8 shows the comparative results in terms of fractional conversion and product yield for both electrocatalytic hydrogenation reaction performed at $\mathrm{Pd}_{0.02} / \mathrm{C} / \mathrm{T}$ and $\mathrm{Pd}_{0.20} / \mathrm{C} / \mathrm{T}$ electrodes and no significantly electrocatalytic hydrogenation reaction at $\mathrm{Pd}_{0.00} / \mathrm{C} / \mathrm{T}$ electrode appears. In addition, the selectivity of diphenylmethanol is still over $90 \%$ irrespectively of the current density examined; the alcohol and alkane derivatives are also obtained, though prevailing the diphenylmethanol with high product yield (see Figure 8), being similar behaviour as that shown for the electrochemical hydrogenation using the $\mathrm{Pd}_{0.02} / \mathrm{C} / \mathrm{T}$ electrode.

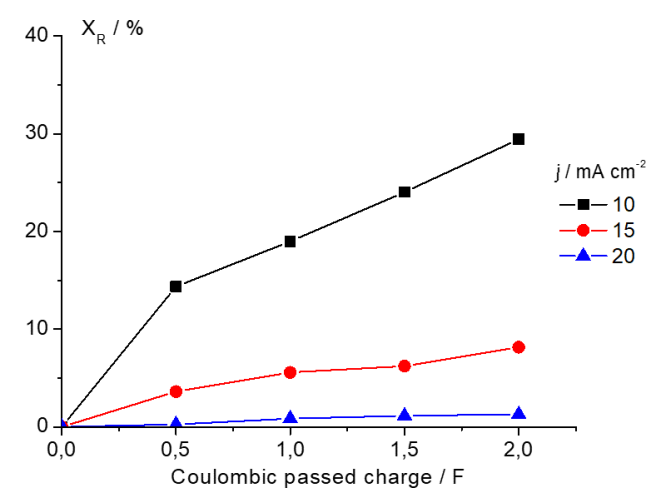

Figure 7: Fractional conversion of benzophenone as a function of coulombic charge passed; $0.5 \mathrm{M}$ benzophenone as starting solution in ethanol/ $\mathrm{H}_{2} \mathrm{O}(90: 10 \mathrm{v} / \mathrm{v})$ plus $0.1 \mathrm{M} \mathrm{H}_{2} \mathrm{SO}_{4} . \mathrm{Pd}_{0.20} / \mathrm{C} / \mathrm{T}$ electrode.

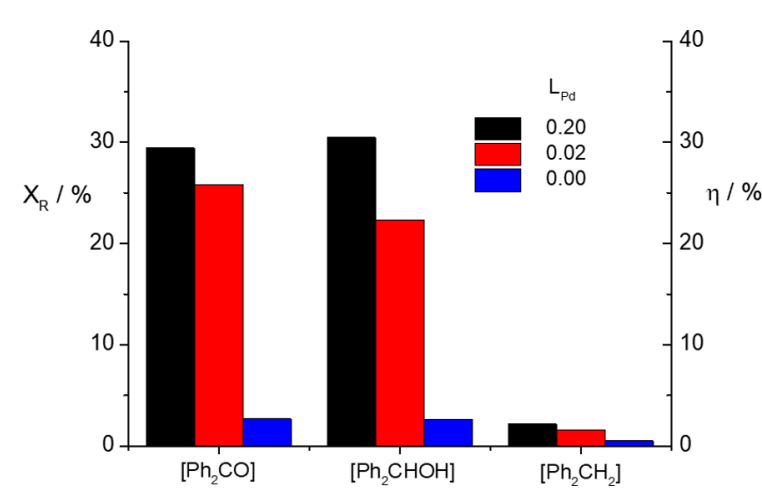

Figure 8: Comparison of fractional conversion $\left(X_{R}\right)$ and product yield ( $\eta$ between $\mathrm{Pd}_{0.02} / \mathrm{C} / \mathrm{T}, \mathrm{Pd}_{0.20} / \mathrm{C} / \mathrm{T}$ and $\mathrm{Pd}_{0.00} / \mathrm{C} / \mathrm{T}$ electrodes. 
The comparison of fractional conversion and product yield displayed in Figure 8 shows that the electrocatalytic hydrogenation of benzophenone is nearly irrespective of the Pd electrocatalytic loading. Indeed, one would respect a much higher fractional conversion of benzophenone when using the $\mathrm{Pd}_{0.20} / \mathrm{C} / \mathrm{T}$ electrode. In other words, the higher Pd electrocatalytic loading, the higher adsorption of the organic molecule, and likely the higher reactivity of the adsorbed organic molecule with adsorbed hydrogen. At this point, we have defined a parameter, $\mathrm{X}_{\mathrm{N}}$, as fractional conversion normalised towards the electrochemically Pd accessible surface area, i.e., Pd accessible sites, according to Equation 3 shown below in order to shed light on the real effect of the Pd loading on the electrochemical hydrogenation of benzophenone.

$$
\mathrm{X}_{\mathrm{N}}=\frac{\mathrm{X}_{\mathrm{R}}}{\mathrm{rf} \cdot A_{\text {geom }}}
$$

This parameter denotes the usefulness of electrocatalytic loading and is expressed as $\%\left(\mathrm{~cm}^{2} \mathrm{Pd}\right)^{-1}$ where, $\mathrm{X}_{\mathrm{R}}$ and $\mathrm{rf}$ have the usual meanings and $\mathrm{A}_{\text {geom }}$ corresponds to geometric area.

We have calculated the $\mathrm{X}_{\mathrm{N}}$ value accordingly to the optimum current density of $10 \mathrm{~mA} \mathrm{~cm} \mathrm{~cm}^{-2}$ for both electrocatalytic loadings. These values are 0.073 and 0.014 for 0.02 and 0.2 ( $\mathrm{mg} \mathrm{Pd}) \mathrm{cm}^{-2}$ respectively, confirming higher electrocatalytic usefulness for lower catalytic loading. By comparing Pd electrocatalytic loadings between 0.02 and 0.2 , only $16 \%$ of the total accessible surface area in Pd electrocatalytic loading of $0.2 \mathrm{mg} \mathrm{cm}^{-2}$ resulted to be active to electrocatalytic hydrogenation of benzophenone. Accessibility problems of benzophenone molecules reaching electroactive sites within a thicker electrocatalytic layer are the most plausible explanation for getting a lower $\mathrm{X}_{\mathrm{N}}$ value. Consequently, an increment of the electrocatalytic layer does not guarantee an enhancement of fractional conversion. For this reason, lower electrocatalytic loadings are the best approach to take into consideration.

Finally, the influence of acidic medium in catholyte solutions was explored to simplify the work-up of the crude mixture from the electrocatalytic hydrogenation of benzophenone. It is worth noticing that acidic medium is a parameter that must be taken into consideration in terms of selectivity for electrocatalytic hydrogenations of several organic compounds. In this regard, we performed the electrochemical hydrogenation of benzophenone in the absence of $0.1 \mathrm{M} \mathrm{H}_{2} \mathrm{SO}_{4}$ in order to investigate the contribution of hydronium ion formation from hydrogen oxidation reaction passing through the polymer electrolyte membrane as the sole hydronium ions source reaching the catholyte compartment. In doing so, the electrocatalytic hydrogenation of benzophenone was performed at $10 \mathrm{~mA} \mathrm{~cm}^{-2}$ using both $\mathrm{Pd}_{0.02} /$ $\mathrm{C} / \mathrm{T}$ and $\mathrm{Pd}_{0.20} / \mathrm{C} / \mathrm{T}$ electrodes in the absence of sulfuric acid. Figure 9 depicts the fractional conversions and product yields as a function of the coulombic charge passed for both electrodes in the absence and presence of $0.1 \mathrm{M} \mathrm{H}_{2} \mathrm{SO}_{4}$ for comparative purposes. Even though no changes were observed in terms of selectivity in the absence of the electrolyte, a remarkable fractional conversion decrease of around $10 \%$ can be calculated. As summary, the sole contribution of hydronium ions originating from the hydrogen oxidation reaction is not enough yet for an optimal performance of the electrocatalytic hydrogenation of benzophenone.

a)

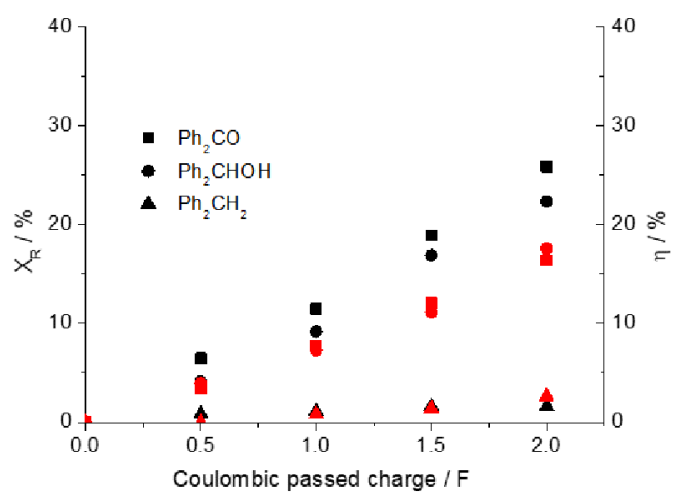

b)

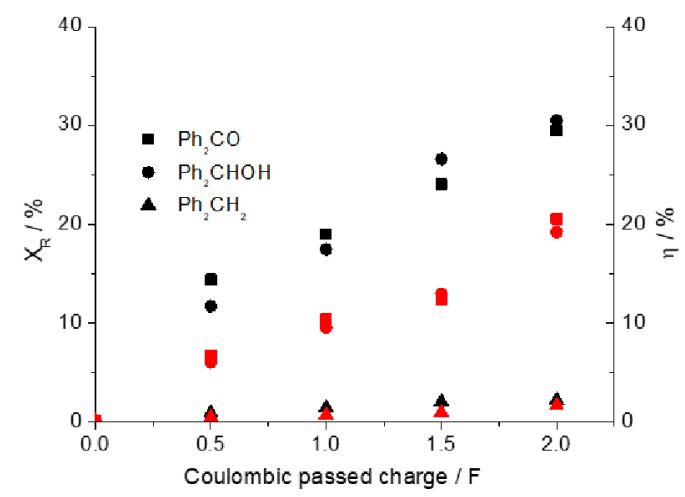

Figure 9: Fractional conversions of benzophenone and product yield of diphenylmethanol at both electrodes. (a) $\mathrm{Pd}_{0.02} / \mathrm{C} / \mathrm{T}$ electrode; (b) $\mathrm{Pd}_{0.20} / \mathrm{C} / \mathrm{T}$ electrode; $0.5 \mathrm{M}$ benzophenone as starting solution in ethanol/water $\left(90: 10 \mathrm{v} / \mathrm{v}\right.$ ) in the presence of $0.1 \mathrm{M} \mathrm{H}_{2} \mathrm{SO}_{4}$ (black symbols) and absence of $\mathrm{H}_{2} \mathrm{SO}_{4}$ (red symbols).

\section{Conclusion}

The electrocatalytic hydrogenation of benzophenone has been performed at pre-pilot scale using a polymer electrolyte membrane electrochemical reactor (PEMER). The benzophenone conversion and diphenylmethanol and diphenylmethane yields are driven mostly by the current density used. Even though the lowest current density favours the benzophenone conversion and the alcohol yield, higher current density leads to a high 
selectivity. In terms of Pd loading within the electrocatalytic layer, no significant difference is achieved with respect to fractional conversion and product yields, however, Pd accessible surface area per weight unit turns out to be enhanced for the lowest electrocatalytic loading, indicating a benzophenone accessibility to the Pd nanoparticulate electrocatalysts.

Hydrogen gas evolution reaction in the cathode compartment can be reused to feed a gas diffusion electrode for the hydrogen oxidation reaction. Moreover, in the absence of an acid medium as supporting electrolyte commonly used at the cathode compartment, the electrocatalytic hydrogenation is feasible by the sole supply of hydronium ions generated at the anode compartment coming from the hydrogen oxidation reaction.

Finally, it is worth noting that the hydrogen oxidation reaction was used as anodic process decreasing cell voltage of the process; besides, the use of hydrogen evolved at the cathode as competitive reaction must be considered as hydrogen source to partially feed the hydrogen anode.

\section{Experimental}

Benzophenone, diphenylmethanol, diphenylmethane, ethanol 96\% (Sigma-Aldrich, Spain) were used without further purification. $\mathrm{K}_{2} \mathrm{PdCl}_{4}$ salt was purchased from Sigma-Aldrich (purity higher than 99\%). Vulcan XC72R carbon material was purchased from Cabot Corporation. The other chemicals were purchased in the highest purity available and used as received. The solutions were prepared with doubly distilled water.

The synthesis of Pd nanoparticles was performed following a procedure previously used in our laboratory and described in the literature [27,28]. Briefly, a $\mathrm{K}_{2} \mathrm{PdCl}_{4}$ salt solution was reduced using $\mathrm{NaBH}_{4}$ as reducing agent in a water-in-oil (w/o) microemulsion in the presence of polyethylene glycol hexadecyl ether, Brij@30 as capping agent and $n$-heptane as organic solvent (water/Brij@30/n-heptane). After precipitation and copiously washing with acetone and water, Pd nanoparticles were supported on Vulcan XC72R to get a nominal $30 \mathrm{wt} \% \mathrm{Pd}$ loading $(\mathrm{Pd} / \mathrm{C}$ electrocatalyst).

The cathode layer was prepared by air-brushing an electrocatalytic ink onto a Toray Paper TGPH-90 (carbonaceous composite paper supplied by Toray Industries Inc., thickness $280 \mu \mathrm{m}$ ). The electrocatalytic ink consisted of Pd nanoparticles supported in Vulcan XC72R 30 wt \% dispersion in isopropanol containing a Nafion dispersion of $5 \mathrm{wt} \%$. All electrodes have a $\mathrm{Pd} / \mathrm{C}$ to Nafion ratio of 60:40 in the electrocatalytic layer with $\mathrm{Pd}$ loadings of 0.20 and $0.02 \mathrm{mg} \mathrm{cm}^{-2}$. Cathodes were named as $\mathrm{Pd}_{\mathrm{x}} / \mathrm{C} / \mathrm{T}$ where $\mathrm{x}$ stands for the Pd loading and $\mathrm{T}$ is the Toray paper support.
Morphology, size and dispersion of Pd nanoparticles in $\mathrm{Pd} / \mathrm{C}$ were analysed by a transmission electron microscopy (TEM) using a JEOL JEM-2012 instrument with an accelerating voltage of $300 \mathrm{kV}$. The TEM was connected with an energy dispersion X-ray (EDX) for the analysis of the Pd nanoparticles. Thermogravimetric analysis (TGA) was performed using a Mettler Toledo model TGA/SDTA851 and /SF/1100 using a heating slope of $10 \mathrm{~K} \mathrm{~min}^{-1}$ from $298 \mathrm{~K}$ to $1023 \mathrm{~K}$ under a $\mathrm{N}_{2}: \mathrm{O}_{2}(4: 1)$ atmosphere. For the characterisation of the $\mathrm{Pd}_{\mathrm{x}} / \mathrm{C} / \mathrm{T}$ scanning electron microscopy (SEM) micrographs were obtained using a Hitachi S-3000N microscope with backscattered electron signal. Electrochemical surface characterisation of the distinct $\mathrm{Pdx} / \mathrm{C} / \mathrm{T}$ electrodes was explored by cyclic voltammetry $(\mathrm{CV}) . \mathrm{CV}$ measurements were performed using a PGSTAT30 Autolab system. A $0.5 \mathrm{~cm} \times 1.0 \mathrm{~cm} \mathrm{Pd}_{\mathrm{x}} / \mathrm{C} / \mathrm{T}$ electrode acted as a working electrode (WE), the counter electrode was a platinum wire and an $\mathrm{Ag} / \mathrm{AgCl}(3.0 \mathrm{M} \mathrm{KCl})$ acted as reference electrode through a Luggin capillary. $\mathrm{CV}$ measurements were performed at room temperature and under argon atmosphere. $\mathrm{CV}$ curves were recorded between 0.1 and $1.2 \mathrm{~V}$ vs $\mathrm{Ag} / \mathrm{AgCl}$ $(3.0 \mathrm{M} \mathrm{KCl})$ with a scan rate of $50 \mathrm{mV} \mathrm{s}^{-1}$ using a $0.5 \mathrm{M}$ $\mathrm{H}_{2} \mathrm{SO}_{4}$ aqueous solution. The electrochemical accessible surface area (ESA) was defined as the Pd electrochemically active surface divided into the total $\mathrm{Pd}$ weight according to the total $\mathrm{Pd}$ loading, expressed in $\left(\mathrm{cm}^{2} \mathrm{Pd}\right)(\mathrm{mg} \mathrm{Pd})^{-1}$, while the roughness factor was defined as the Pd electrochemically active surface divided by the geometric total area, expressed in $\left(\mathrm{cm}^{2} \mathrm{Pd}\right) \mathrm{cm}^{-2}$ (vide supra).

Electrosynthesis reactions were performed using a $25 \mathrm{~cm}^{2}$ PEM single cell fuel cell (EFC-25-01 model from ElectroChem Inc.) acting as polymer electrolyte membrane electrochemical reactor (PEMER), as depicted in Figure 10. Such an electrochemical reactor consisted of (i) a $\mathrm{Pd}_{\mathrm{x}} / \mathrm{C} / \mathrm{T}$ cathode, (ii) an ETEK gas diffusion-type EFGC (Pt/C/T) with a 40 wt \% of Pt with respect to the amount of carbon, and a Pt electrocatalytic loading of $2.0 \mathrm{mg} \mathrm{cm}^{-2}$ as anode to carry out the hydrogen oxidation reaction, and finally, (iii) a Nafion 117 cation exchange membrane in contact between both electrodes acting as solid polymer electrolyte.

The catholyte solutions for the electrochemical hydrogenation of benzophenone consisted of either (i) $0.5 \mathrm{M}$ benzophenone in ethanol $96 \% /$ water $(90: 10 \mathrm{v} / \mathrm{v})$ and $0.1 \mathrm{M} \mathrm{H}_{2} \mathrm{SO}_{4}$, or (ii) $0.5 \mathrm{M}$ benzophenone in ethanol $96 \% /$ water $(90: 10 \mathrm{v} / \mathrm{v})$ in the absence of the sulfuric acid electrolyte in order to explore the influence of the medium acidity upon the electrochemical hydrogenation.

A peristaltic pump Ismatel Reglo DIG MS/CA 2-8 provided a catholyte flow of $12 \mathrm{~mL} \mathrm{~min}^{-1}$ through the cathodic compartment and the total catholyte volume was $40 \mathrm{~mL}$. At the same 


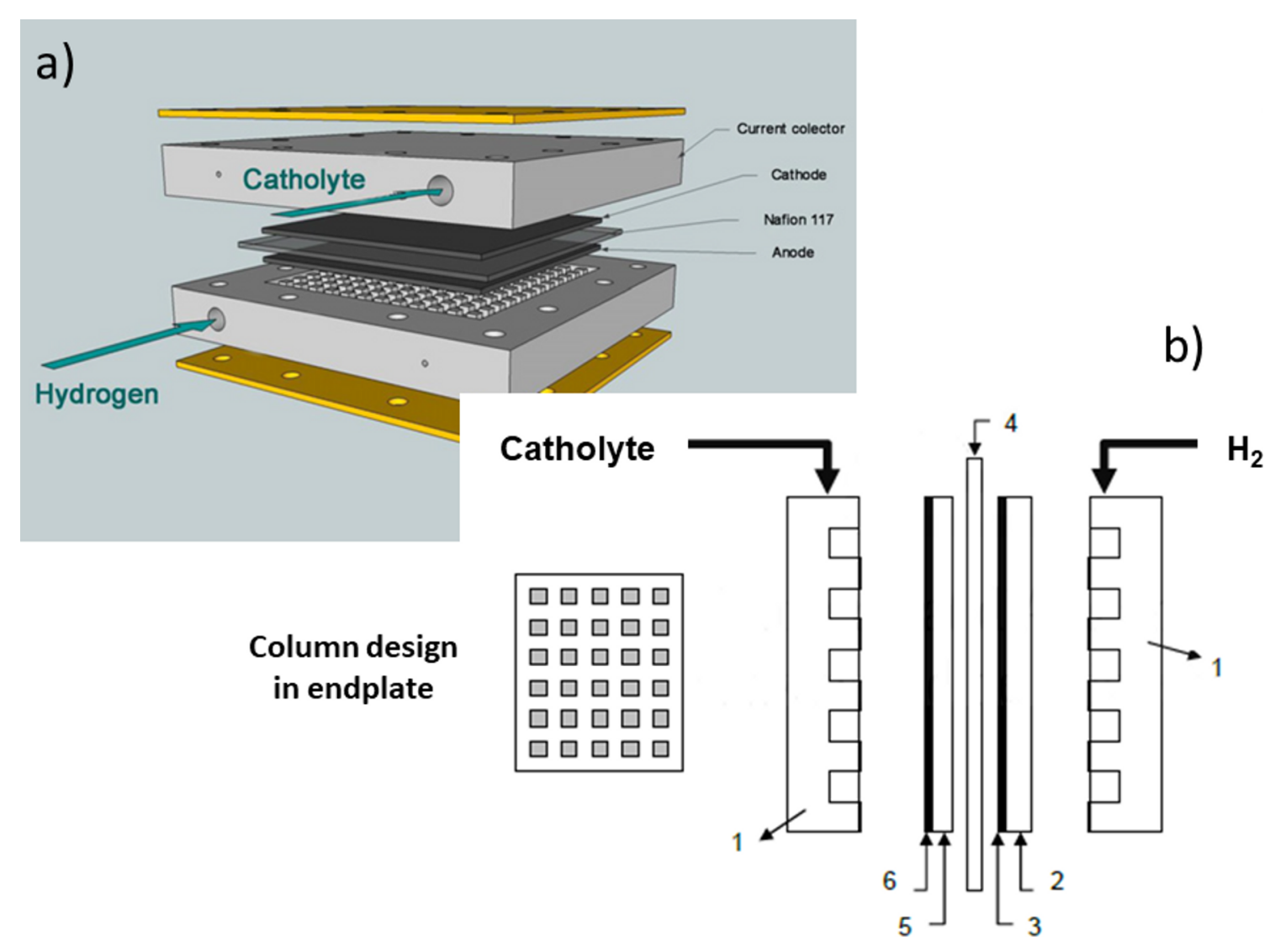

Figure 10: (a) General scheme of a PEMER; (b) itemisation of the main parts of PEMER: 1) endplates, 2) gas diffusion electrode, 3) Pt electrocatalytic layer, 4) polymer electrolyte membrane (solid polymer electrolyte), 5) carbonaceous support (Toray paper TGPH-90), 6) Pd/C electrocatalytic layer.

time, hydrogen (Praxair, purity: 99.999\%) was fed to the anodic

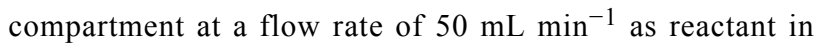
hydrogen oxidation reaction, using a MTS-module A-150 from ElectroChem Inc. Electrocatalytic hydrogenation reactions were carried out at constant current densities of 10,15 and $20 \mathrm{~mA} \mathrm{~cm}{ }^{-2}$ considering a projected geometric area of $25 \mathrm{~cm}^{2}$ for both $\mathrm{Pd}_{0.02} / \mathrm{C} / \mathrm{T}$ and $\mathrm{Pd}_{0.20} / \mathrm{C} / \mathrm{T}$ electrodes using a potentiostat OrigaFlex OGF05A. Total coulombic charge passed was set at 2 Faradays for each experiment. The cell voltage was recorded during each experiment. All preparative electrochemical hydrogenations were carried out at room temperature. In this case, counter electrode plug was connected to reference electrode one and chronopotentiometries were performed registering cell voltage versus time.

The fractional conversion of benzopheneone and product yield and selectivity of final products from the electrocatalytic hydrogenation of benzophenone was examined as a function of current density and Pd loading in the electrocatalytic layer. On doing so, the catholyte solution was analysed by using a highresolution liquid chromatograph (HPLC Agilent 1200) with a
Hypersil ODS column $4 \times 250 \mathrm{~mm}, 5 \mu \mathrm{m}$ particle size (Agilent Technologies). An acetonitrile/water $(1: 1 \mathrm{v} / \mathrm{v}$, acetonitrile isocratic HPLC grade and water from Elix 3 Millipore system) was used as mobile phase. The flow rate was $1 \mathrm{~mL} \mathrm{~min}^{-1}$; the injection volume was $100 \mu \mathrm{L}$ and the working temperature was $303 \mathrm{~K}$. Such experimental conditions provided linear calibration curves between 20 and 100 ppm with all benzophenone, diphenylmethanol and diphenylmethane standard organic solutions. Preparative electrosyntheses were given as fractional conversion $\left(\mathrm{X}_{\mathrm{R}}\right)$ of benzophenone $\left(\mathrm{Ph}_{2} \mathrm{CO}\right)$ and product yield $(\eta)$ of diphenylmethanol $\left(\mathrm{Ph}_{2} \mathrm{CHOH}\right)$ and diphenylmethane $\left(\mathrm{Ph}_{2} \mathrm{CH}_{2}\right)$. Selectivity values $(\xi)$ of diphenylmethanol and diphenylmethane were also calculated. For comparative purposes, a free-Pd electrocatalytic layer $\left(\mathrm{Pd}_{0.00} / \mathrm{C} / \mathrm{T}\right)$ cathode was also considered for the electrocatalytic hydrogenation of $\mathrm{Ph}_{2} \mathrm{CO}$.

\section{Acknowledgements}

Authors thank the Ministerio de Economia y Competitividad MINECO, Spain for its financial support by the research projects CTQ2013-48280-C3-3-R and CTQ2016-76231-C2-2-R. 


\section{ORCID ${ }^{\circledR}$ iDs}

Cristina Mozo Mulero - https://orcid.org/0000-0002-6490-9710

Alfonso Sáez - https://orcid.org/0000-0002-2949-6711

Jesús Iniesta - https://orcid.org/0000-0003-4350-2169

Vicente Montiel - https://orcid.org/0000-0003-2353-2993

\section{References}

1. Chen, B.; Dingerdissen, U.; Krauter, J. G. E.; Lansink Rotgerink, H. G. J.; Möbus, K.; Ostgard, D. J.; Panster, P.; Riermeier, T. H.; Seebald, S.; Tacke, T.; Trauthwein, H. Appl. Catal., A 2005, 280, 17-46. doi:10.1016/j.apcata.2004.08.025

2. Rilander, P. N. Hydrodenation Methods; Academic Press, 1985; p 193.

3. Magnoux, P.; Lavaud, N.; Guisnet, M. Top. Catal. 2000, 13, 291-299. doi:10.1023/a:1009009727910

4. Yoshida, J.-i.; Kataoka, K.; Horcajada, R.; Nagaki, A. Chem. Rev. 2008, 108, 2265-2299. doi:10.1021/cr0680843

5. Cirtiu, C. M.; Brisach-Wittmeyer, A.; Ménard, H. Catal. Commun. 2007, 8, 751-754. doi:10.1016/j.catcom.2006.09.014

6. Coche, L.; Moutet, J. C. J. Am. Chem. Soc. 1987, 109, 6887-6889. doi:10.1021/ja00256a072

7. Moutet, J.-C. Org. Prep. Proced. Int. 1992, 24, 309-325. doi:10.1080/00304949209355892

8. Pintauro, P. N.; Bontha, J. R. J. Appl. Electrochem. 1991, 21, 799-804. doi:10.1007/bf01402817

9. Polcaro, A. M.; Dernini, M. S.; Palmas, S. Electrochim. Acta 1992, 37, 365-367. doi:10.1016/0013-4686(92)85025-G

10. Polcaro, A. M.; Palmas, S.; Dernini, S. Electrochim. Acta 1993, 38 , 199-203. doi:10.1016/0013-4686(93)85129-M

11. Dabo, P.; Cyr, A.; Lessard, J.; Brossard, L.; Ménard, H. Can. J. Chem. 1999, 77, 1225-1229. doi:10.1139/v99-120

12. Laplante, F.; Brossard, L.; Ménard, H. Can. J. Chem. 2003, 81, 258-264. doi:10.1139/v03-027

13. St-Pierre, G.; Chagnes, A.; Bouchard, N.-A.; Harvey, P. D.; Brossard, L.; Ménard, H. Langmuir 2004, 20, 6365-6373. doi:10.1021/la048977v

14. Cirtiu, C. M.; Hassani, H. O.; Bouchard, N.-A.; Rowntree, P. A.; Ménard, H. Langmuir 2006, 22, 6414-6421. doi:10.1021/la0519002

15. Cirtiu, C. M.; Brisach-Wittmeyer, A.; Ménard, H. J. Catal. 2007, 245, 191-197. doi:10.1016/j.jcat.2006.10.010

16. Osa, T.; Matsue, T.; Yokozawa, A.; Yamada, T. Denki Kagaku 1986, $54,484$.

17. Osa, T.; Matsue, T.; Yokozawa, A.; Yamada, T. Denki Kagaku 1984, $52,629$.

18. Borup, R.; Meyers, J.; Pivovar, B.; Kim, Y. S.; Mukundan, R.; Garland, N.; Myers, D.; Wilson, M.; Garzon, F.; Wood, D.; Zelenay, P.; More, K.; Stroh, K.; Zawodzinski, T.; Boncella, J.; McGrath, J. E.; Inaba, M.; Miyatake, K.; Hori, M.; Ota, K.; Ogumi, Z.; Miyata, S.; Nishikata, A.; Siroma, Z.; Uchimoto, Y.; Yasuda, K.; Kimijima, K.-i.; Iwashita, N. Chem. Rev. 2007, 107, 3904-3951. doi:10.1021/cr050182|

19. Litster, S.; McLean, G. J. Power Sources 2004, 130, 61-76. doi:10.1016/j.jpowsour.2003.12.055

20. Smitha, B.; Sridhar, S.; Khan, A. A. J. Membr. Sci. 2005, 259, 10-26. doi:10.1016/j.memsci.2005.01.035

21. Montiel, V.; Sáez, A.; Expósito, E.; García-García, V.; Aldaz, A. Electrochem. Commun. 2010, 12, 118-121. doi:10.1016/j.elecom.2009.11.002
22. Sáez, A.; García-García, V.; Solla-Gullón, J.; Aldaz, A.; Montiel, V. Electrochem. Commun. 2013, 34, 316-319.

doi:10.1016/j.elecom.2013.07.018

23. Sáez, A.; García-García, V.; Solla-Gullón, J.; Aldaz, A.; Montiel, V. Electrochim. Acta 2013, 91, 69-74. doi:10.1016/j.electacta.2012.12.097

24. Vilar, M.; Oliveira, J. L.; Navarro, M. Appl. Catal., A 2010, 372, 1-7. doi:10.1016/j.apcata.2009.09.041

25. Villalba, M.; Bossi, M. L.; Calvo, E. J. Phys. Chem. Chem. Phys. 2015, 17, 10086-10092. doi:10.1039/C5CP00225G

26. Villalba, M.; del Pozo, M.; Calvo, E. J. Electrochim. Acta 2015, 164, 125-131. doi:10.1016/j.electacta.2015.02.113

27. Solla-Gullón, J.; Montiel, V.; Aldaz, A.; Clavilier, J. J. Electrochem. Soc. 2003, 150, E104-E109. doi:10.1149/1.1534600

28. Solla-Gullón, J.; Rodes, A.; Montiel, V.; Aldaz, A.; Clavilier, J. J. Electroanal. Chem. 2003, 554-555, 273-284. doi:10.1016/S0022-0728(03)00214-6

29. Fang, L.-I.; Tao, Q.; Li, M.-f.; Liao, L.-w.; Chen, D.; Chen, Y.-x. Chin. J. Chem. Phys. 2010, 23, 543-548. doi:10.1088/1674-0068/23/05/543-548

\section{License and Terms}

This is an Open Access article under the terms of the Creative Commons Attribution License (http://creativecommons.org/licenses/by/4.0), which permits unrestricted use, distribution, and reproduction in any medium, provided the original work is properly cited.

The license is subject to the Beilstein Journal of Organic Chemistry terms and conditions:

(https://www.beilstein-journals.org/bjoc)

The definitive version of this article is the electronic one which can be found at: doi: $10.3762 /$ bjoc. 14.40 